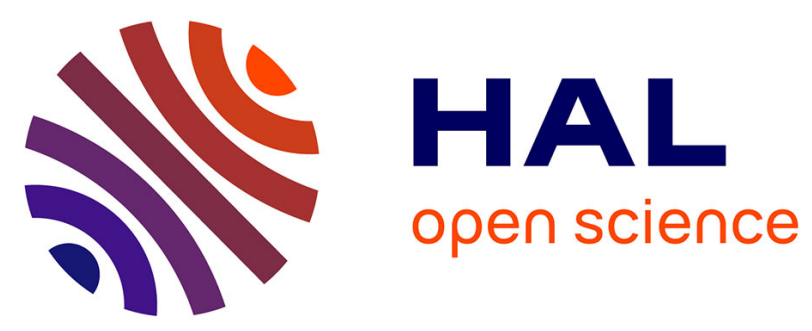

\title{
The analysis of the impact of carbon source-sink relationships on flowering patterns reveals that apple tree growth and functioning are determined by mechanisms occurring at the tree and shoot scales
}

Benoit Pallas, Jérome Ngao, Sébastien S. Martinez, Jean-Jacques Kelner, Evelyne E. Costes

\section{To cite this version:}

Benoit Pallas, Jérome Ngao, Sébastien S. Martinez, Jean-Jacques Kelner, Evelyne E. Costes. The analysis of the impact of carbon source-sink relationships on flowering patterns reveals that apple tree growth and functioning are determined by mechanisms occurring at the tree and shoot scales. 11. Symposium on Integrating Canopy, Rootstockand Environmental Physiology in Orchard Systems, Aug 2016, Bologna, France. hal-02743276

\section{HAL Id: hal-02743276 \\ https://hal.inrae.fr/hal-02743276}

Submitted on 3 Jun 2020

HAL is a multi-disciplinary open access archive for the deposit and dissemination of scientific research documents, whether they are published or not. The documents may come from teaching and research institutions in France or abroad, or from public or private research centers.
L'archive ouverte pluridisciplinaire HAL, est destinée au dépôt et à la diffusion de documents scientifiques de niveau recherche, publiés ou non, émanant des établissements d'enseignement et de recherche français ou étrangers, des laboratoires publics ou privés.

\section{(c)(2)}

Distributed under a Creative Commons CCO - Public Domain Dedication| 4.0 International 


\title{
Analysis of the relationships between shoot types, flowering patterns and source-sink relationships in apple trees.
}

\author{
B. Pallas ${ }^{1}$, J-J Kelner ${ }^{1}$, S. Bluy ${ }^{1}$, S. Martinez ${ }^{1}$, J. Ngao ${ }^{2}$ \& E. Costes ${ }^{1}$ \\ ${ }^{1}$ INRA, UMR AGAP, ${ }^{2}$ INRA, UMR PIAF
}

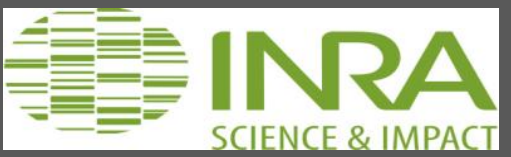

QפOR 


\section{Context (1)}

Large genotypic variability of bearing patterns (alternating, regular, irregular) in apple trees.

4 types of bearing pattern (Durand et al., 2013) : biennial, irregular, regular (bourse over bourse), regular (with desynchronized branches).
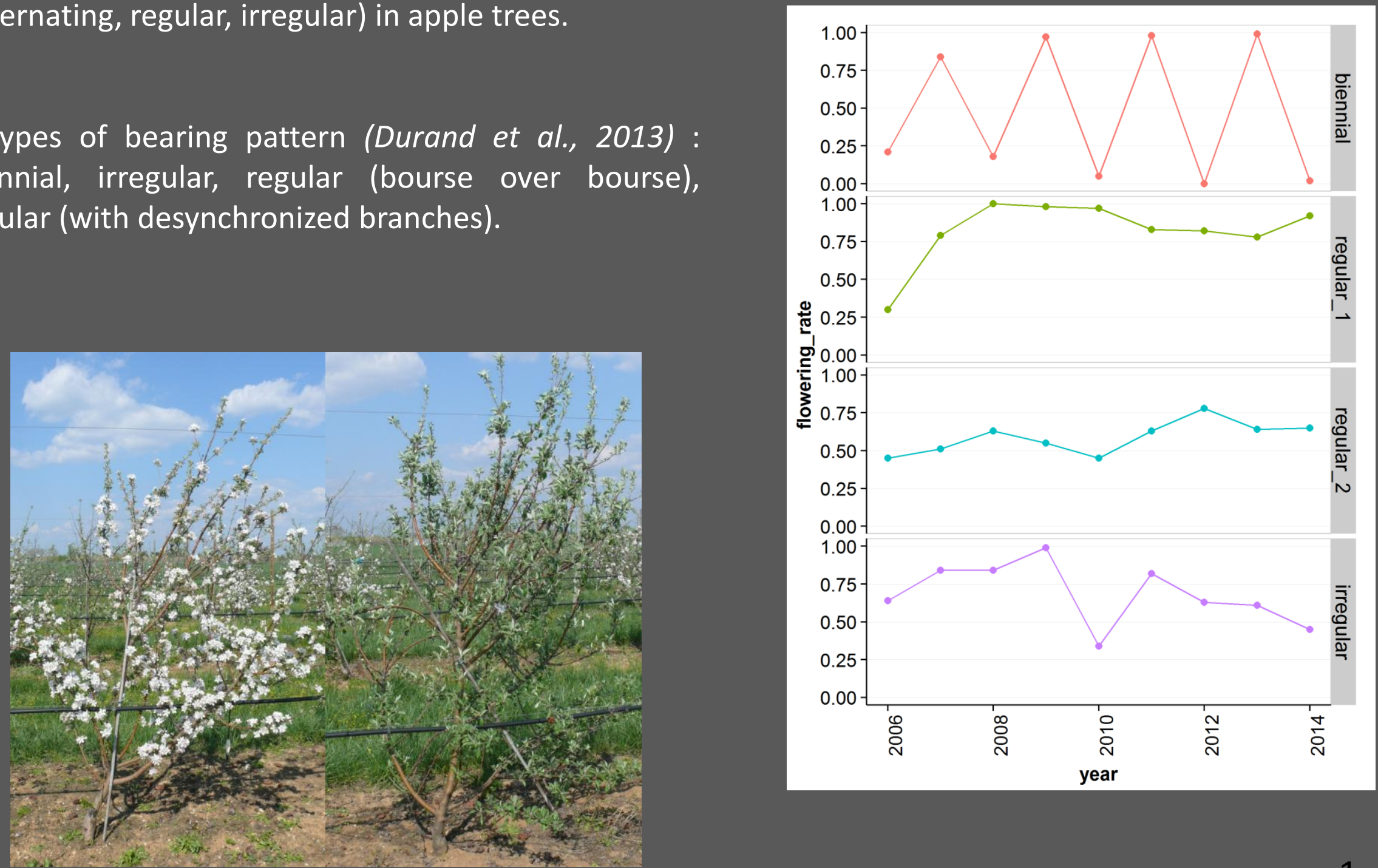


\section{Context (2)}

- The variability in bearing pattern is mainly associated with floral induction in meristem that occurs the year before flowering.

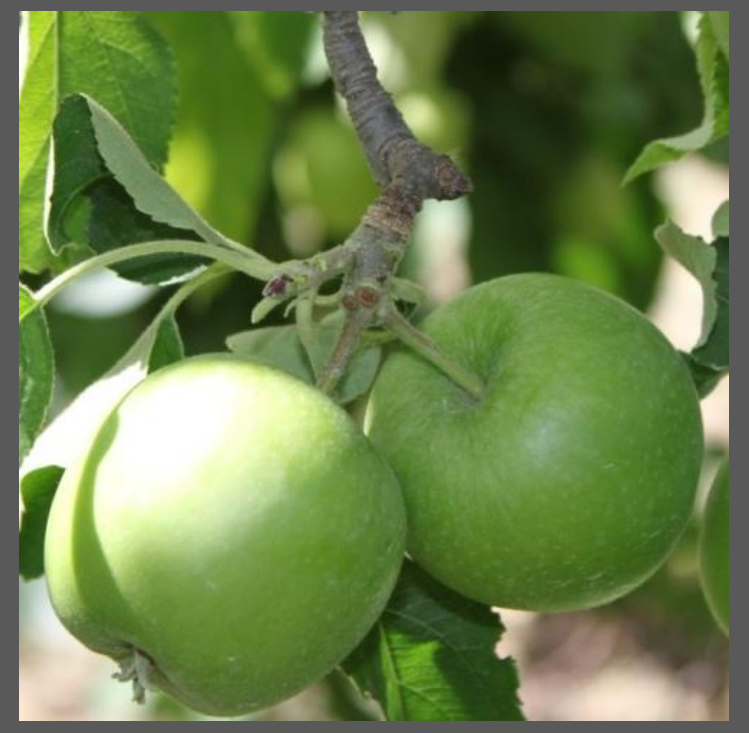




\section{Context (2)}

- The variability in bearing pattern is mainly associated with floral induction in meristem that occurs the year before flowering.

- Overlap of fruit development and floral induction in shoot meristem.

Two main hypotheses exists to explain the variability in floral induction :

-Hormonal signal (coming from fruits and inhibiting floral induction). (Bangerth, 2006)

- The fruit carbon demand can reduce carbon availability in meristem and can affect floral induction.

(Nielsen and Denis, 2000)

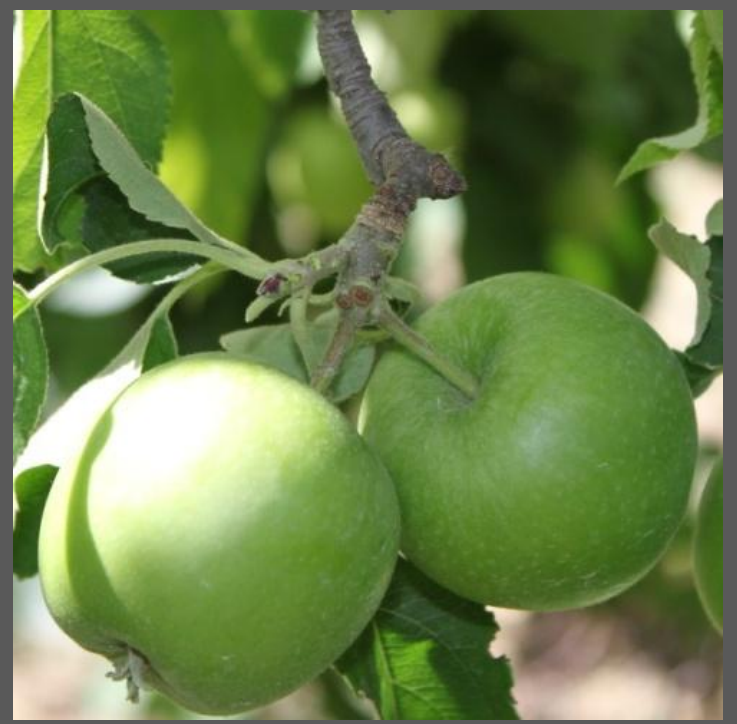




\section{Objectives}

General objective: analyze the carbon source-sink relationships of genotypes with contrasted bearing patterns.

- Two main questions were adressed :

1. What is the impact of fruit development on carbohydrate supply, carbohydrate storage and transport?

2. At which scale of plant organization the tree adjusts its functionning to contrasted crop loads? / What is the importance of the type of shoot (vegetative vs bourse shoots) on the carbon relationship?

Performed by comparing vegetative and bourse shoots growing in different tree crop load conditions. 


\section{Plant material}

- 8-year old F1 segregating population (X3263 x Belrene). 370 individuals with one or two replicates per genotype planted in Montpellier (France)

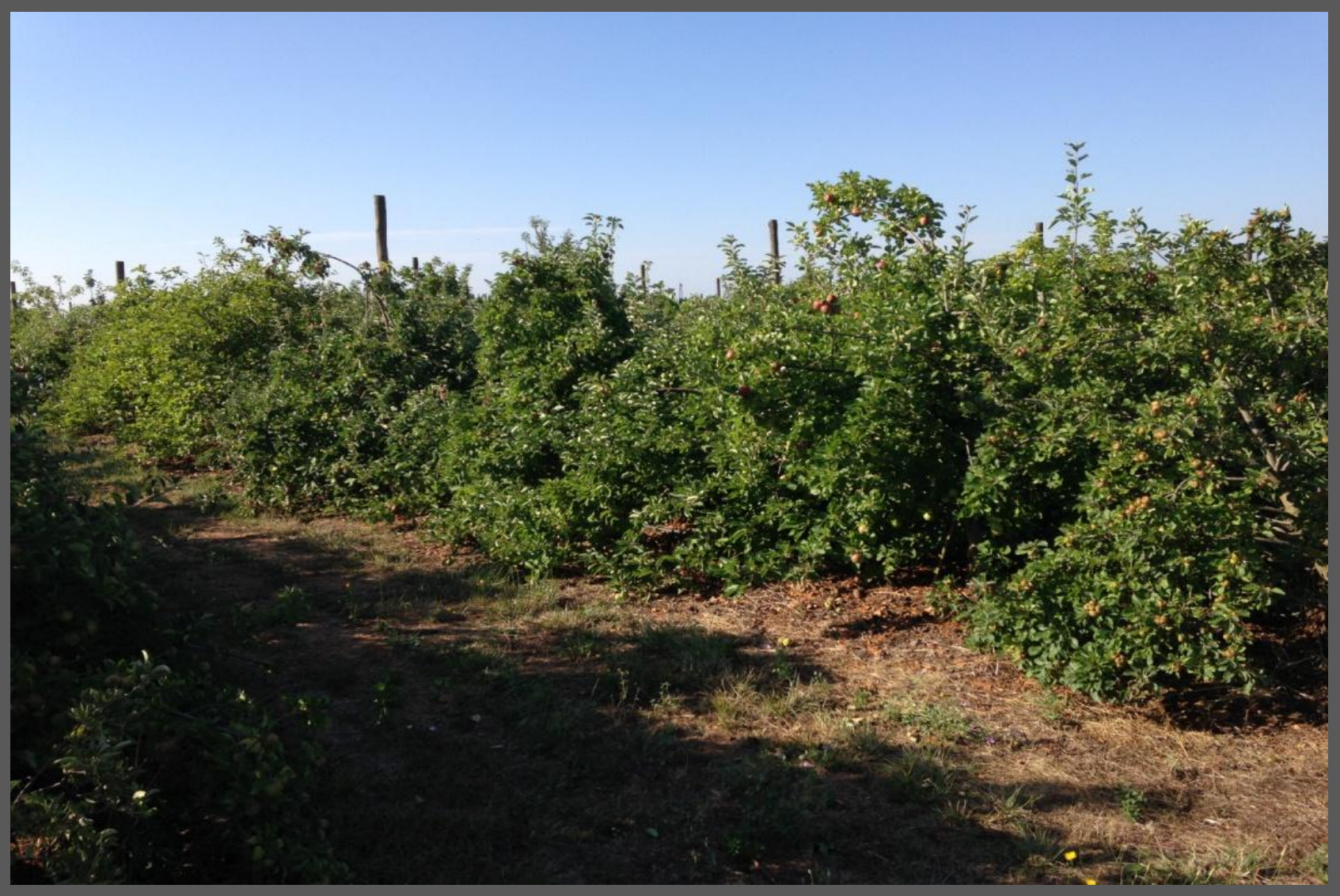


- 8-year old F1 segregating population (X3263 x Belrene). 370 individuals with one or two replicates per genotype.

- Determination of genotype classes for production behaviors.

According to indicators computed at the plant scale. (BBI, autocov) (Durand et al. 2013)

- Regular / Irregular / Biennial

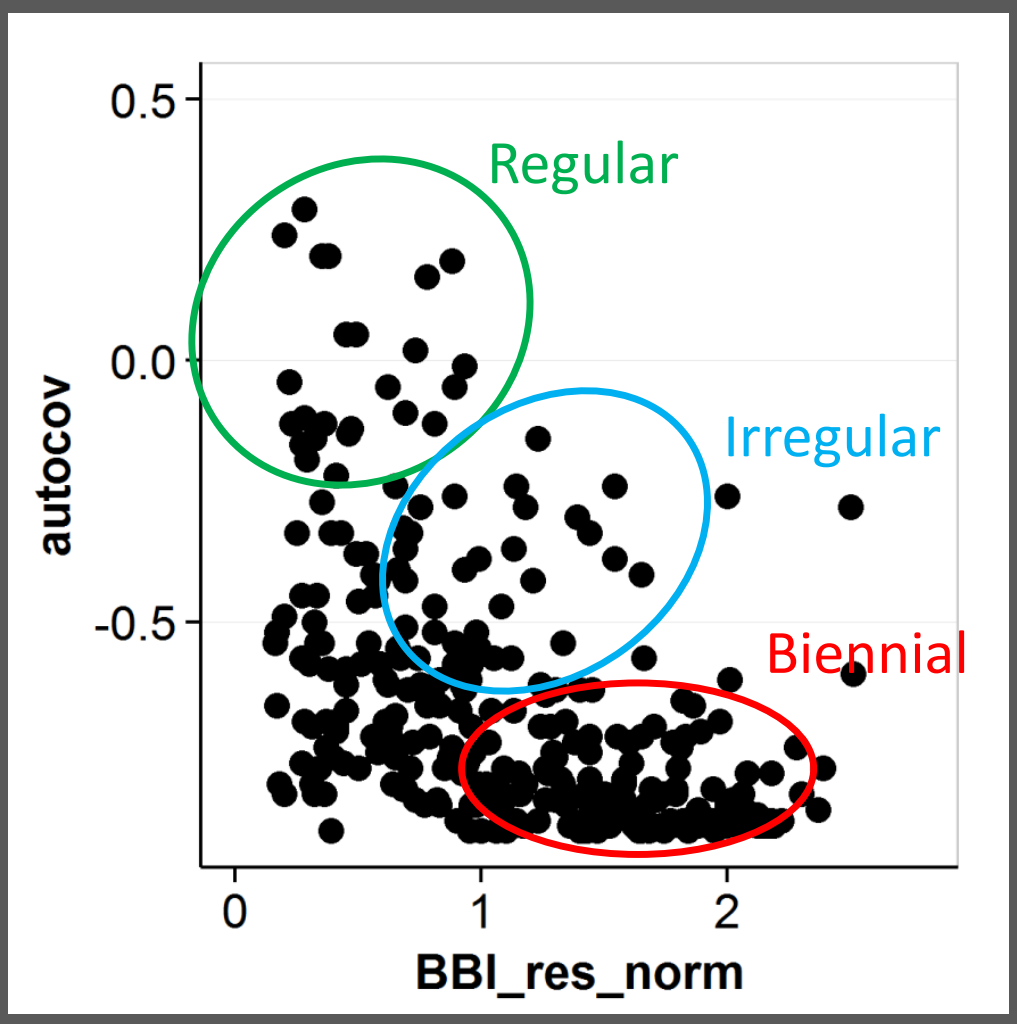


- 8-year old F1 segregating population (X3263 x Belrene). 370 individuals with one or two replicates per genotype.

- Determination of genotype classes for production behaviors.

According to indicators computed at the plant scale. (BBI, autocov)

- Regular / Irregular / Biennial

According to indicators computed at the shoot scale. (entropy)

- Regular (bourse over bourse or desynchronized)
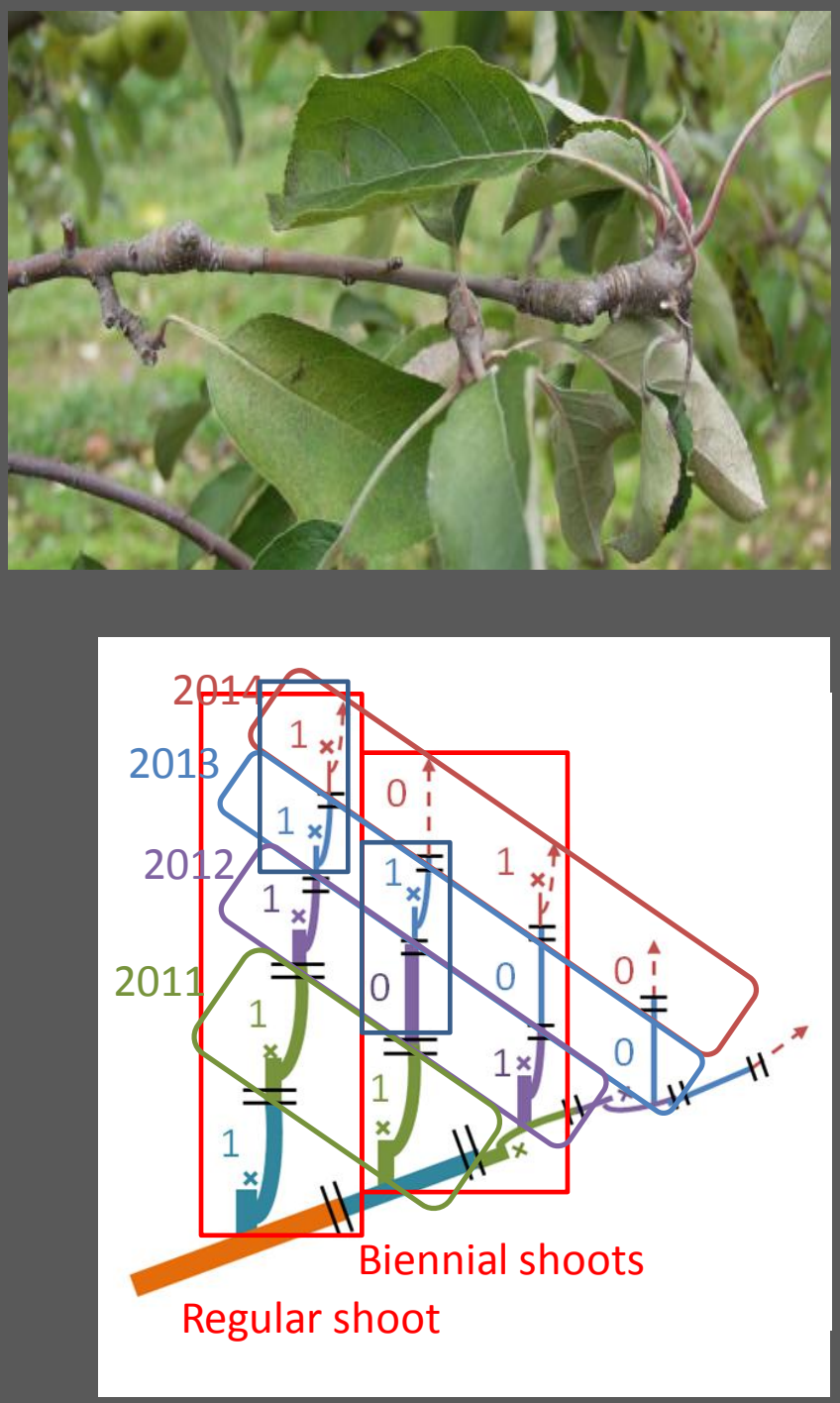


\section{Plant material}

- 8-year old F1 segregating population (X3263 x Belrene). 370 individuals with one or two replicates per genotype.

- Determination of genotype classes for production behaviors.

According to indicators computed at the plant scale. (BBI, autocov)

- Regular / Irregular / Biennial

According to indicators computed at the shoot scale. (entropy)

- Regular (bourse over bourse or desynchronized)

PCA with bearing indexes and mean production

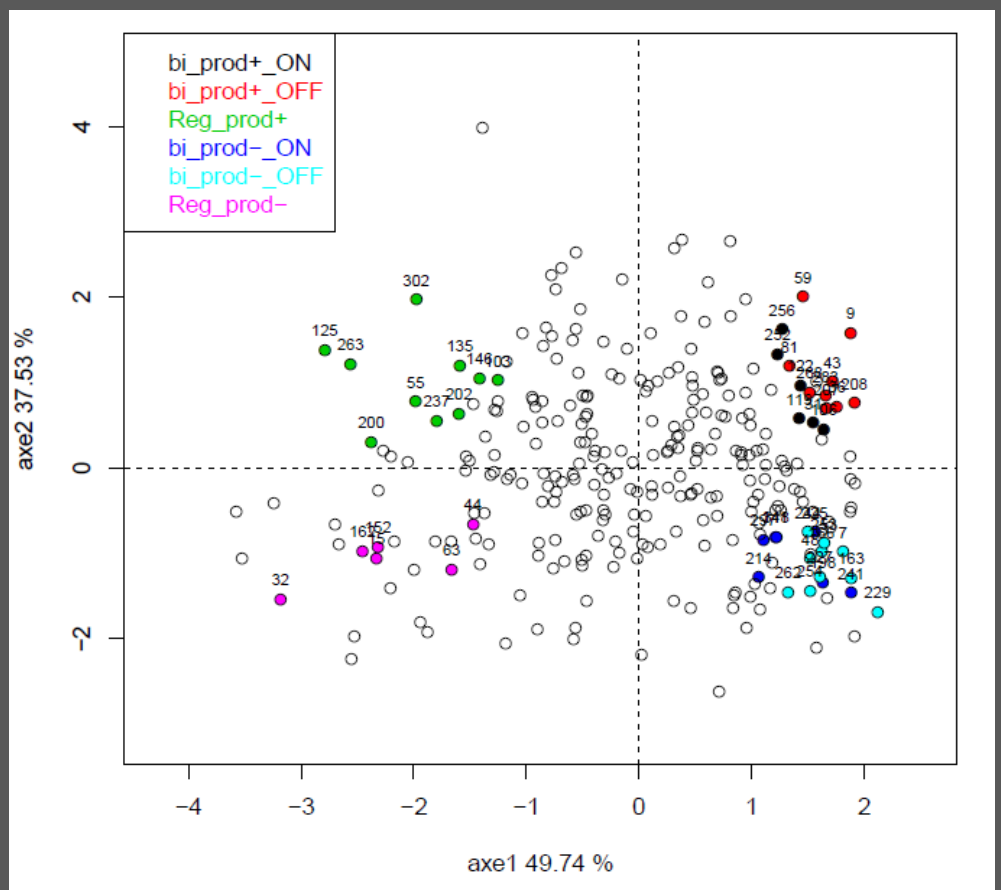

Multivariate analysis including yield variables to determine a sub population for the study 


\section{Physiological measurements}

Tree crop load

\section{(Global context)}

\begin{tabular}{cccc}
\hline & & & \\
\hline Genotype & Type & $\begin{array}{c}2014 \\
\text { Crop load } \\
\text { (nb/TCSA) }\end{array}$ & $\begin{array}{c}2015 \\
\text { Crop load } \\
\text { (nb/TCSA) }\end{array}$ \\
\hline 42 & desynchro & 5.05 & 3.87 \\
$146 \mathrm{~b}$ & desynchro & 1.36 & 1.47 \\
246 & desynchro & 2.72 & 5.83 \\
174 & desynchro & 4.11 & 4.66 \\
\hline 119 & irregular & 0 & 4.51 \\
238 & irregular & 0 & 5.25 \\
$179 a$ & irregular & 0.39 & 7.94 \\
72 & irregular & 0.37 & 7.21 \\
\hline 303 & irregular & 8.77 & 0.99 \\
222 & irregular & 6.99 & 0.56 \\
36 & irregular & 7.44 & 0.06 \\
76 & irregular & 9.99 & 0.15 \\
\hline
\end{tabular}

- 2 years of measurements (2014 - 2015).

- 8 biennial genotypes and 4 regular " desynchronized » genotypes. 


\section{Physiological measurements}

Tree crop load

(Global context)

\begin{tabular}{|c|c|c|c|}
\hline Genotype & Type & $\begin{array}{c}2014 \\
\text { Crop load } \\
\text { (nb/TCSA) }\end{array}$ & $\begin{array}{c}2015 \\
\text { Crop load } \\
\text { (nb/TCSA) }\end{array}$ \\
\hline 42 & desynchro & 5.05 & 3.87 \\
\hline $146 b$ & desynchro & 1.36 & 1.47 Medium \\
\hline 246 & desynchro & 2.72 & 5.83 crop load \\
\hline 174 & desynchro & 4.11 & 4.66 \\
\hline 119 & irregular & 0 & 4.51 \\
\hline 238 & irregular & ${ }^{0}$ OFF & ${ }^{5.25} \mathrm{ON}$ \\
\hline 179a & irregular & 0.39 & 7.94 \\
\hline 72 & irregular & & \\
\hline 303 & irregular & 8.77 & 0.99 \\
\hline 222 & irregular & 6.99 & 0.56 \\
\hline 36 & irregular & $7.44^{O N}$ & $0.06^{O F F}$ \\
\hline 76 & irregular & 9.99 & 0.15 \\
\hline
\end{tabular}

- 2 years of measurements (2014 - 2015).

- 8 biennial genotypes and 4 regular " desynchronized » genotypes. 


\section{Physiological measurements}

Tree crop load

\section{(Global context)}

\begin{tabular}{cccc}
\hline & & & \\
\hline Genotype & Type & $\begin{array}{c}2014 \\
\text { Crop load } \\
\text { (nb/TCSA) }\end{array}$ & $\begin{array}{c}2015 \\
\text { Crop load } \\
\text { (nb/TCSA) }\end{array}$ \\
\hline 42 & desynchro & 5.05 & 3.87 \\
$146 \mathrm{~b}$ & desynchro & 1.36 & 1.47 \\
246 & desynchro & 2.72 & 5.83 \\
174 & desynchro & 4.11 & 4.66 \\
\hline 119 & irregular & 0 & 4.51 \\
238 & irregular & 0 & 5.25 \\
$179 a$ & irregular & 0.39 & 7.94 \\
72 & irregular & 0.37 & 7.21 \\
\hline 303 & irregular & 8.77 & 0.99 \\
222 & irregular & 6.99 & 0.56 \\
36 & irregular & 7.44 & 0.06 \\
76 & irregular & 9.99 & 0.15 \\
\hline & & &
\end{tabular}

- 2 years of measurements (2014 - 2015).

- 8 biennial genotypes and 4 regular " desynchronized » genotypes.

No regular " bourse over bourse " genotype with a good production in the progeny. 


\section{Physiological measurements}

Tree crop load

(Global context)

$+$

Shoot type

(Local context)

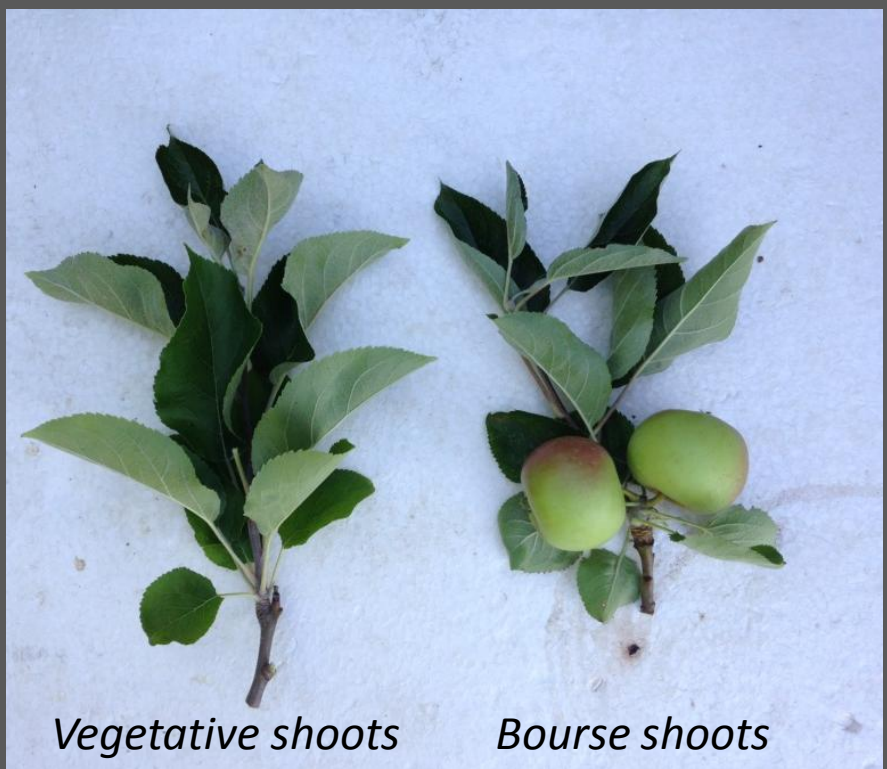

- 2 years of measurements (2014 - 2015).

- 8 biennial genotypes and 4 regular " desynchronized » genotypes.

- Measurements were performed on bourse (ON and desynchronized trees) and vegetative shoots (OFF and desynchronized trees).

- Four « treatments » were defined

1- Bourse shoots in ON trees: ON_F

2-Bourse shoots in desynchronized regular trees : Desynchro_F 3- Vegetative shoots in OFF trees : OFF_V

4-Vegetative shoots in desynchronized trees : Desynchro_V 


\section{Physiological measurements}

- Estimation of source activity (photosynthesis measurements under non limiting environmental conditions. (3-6 reps per tree and harvest dates)

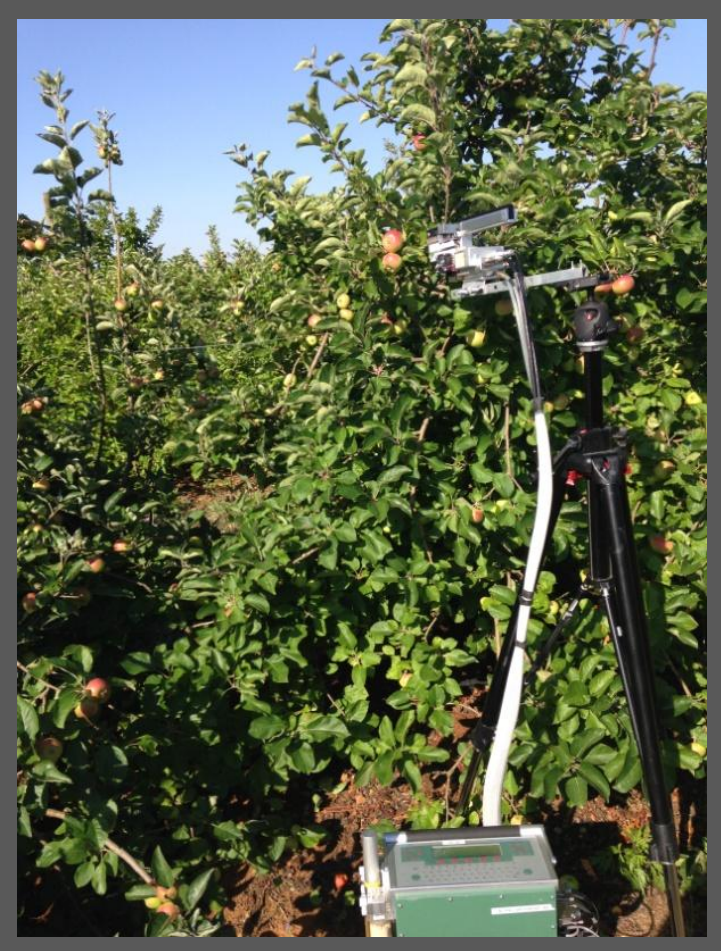




\section{Physiological measurements}

- Estimation of source activity (photosynthesis measurements under non limiting environmental conditions. (3-6 reps per tree and harvest dates)

- NSC analysis on 1 year-old shoots, internodes of annual shoots and leaves.

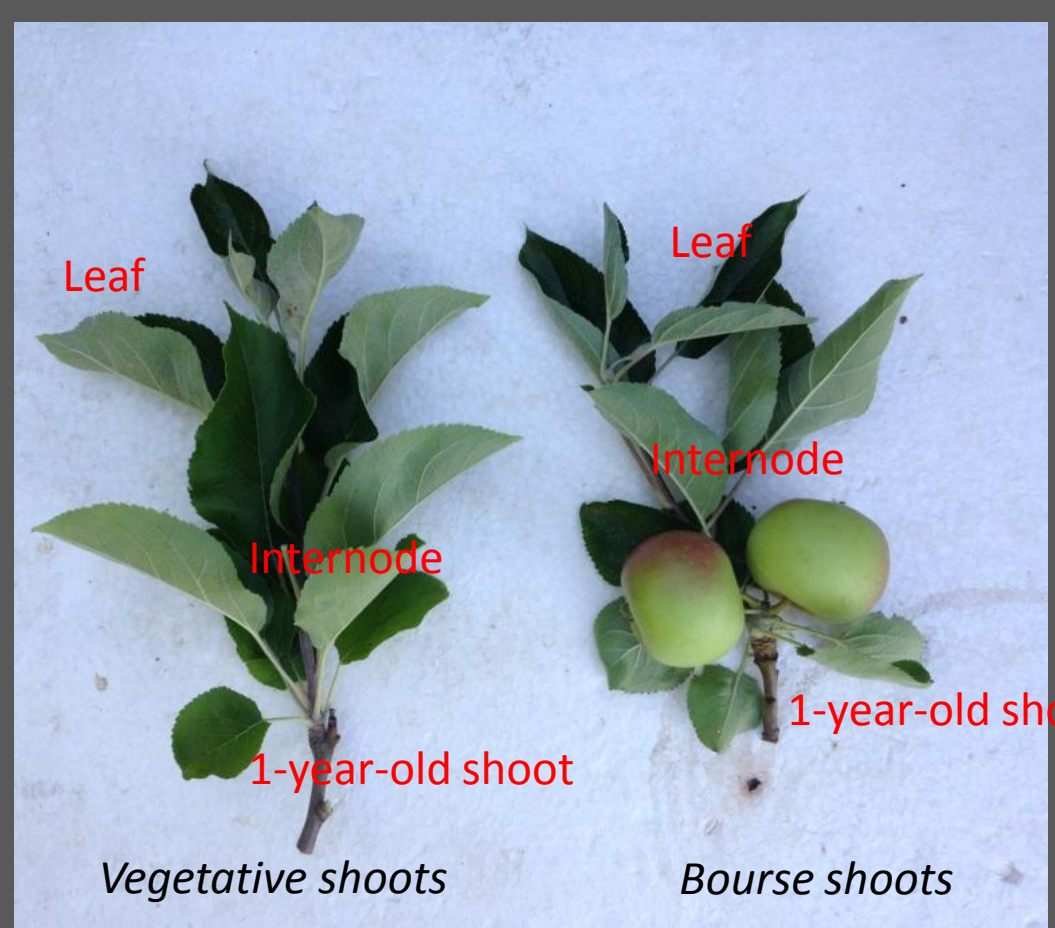




\section{Physiological measurements}

- Estimation of source activity (photosynthesis measurements under non limiting environmental conditions. (3-6 reps per tree and harvest dates)

- NSC analysis on 1 year-old shoots, internodes of annual shoots and leaves.

- Morphological measurements (leaf number, shoot length, SLA ... )

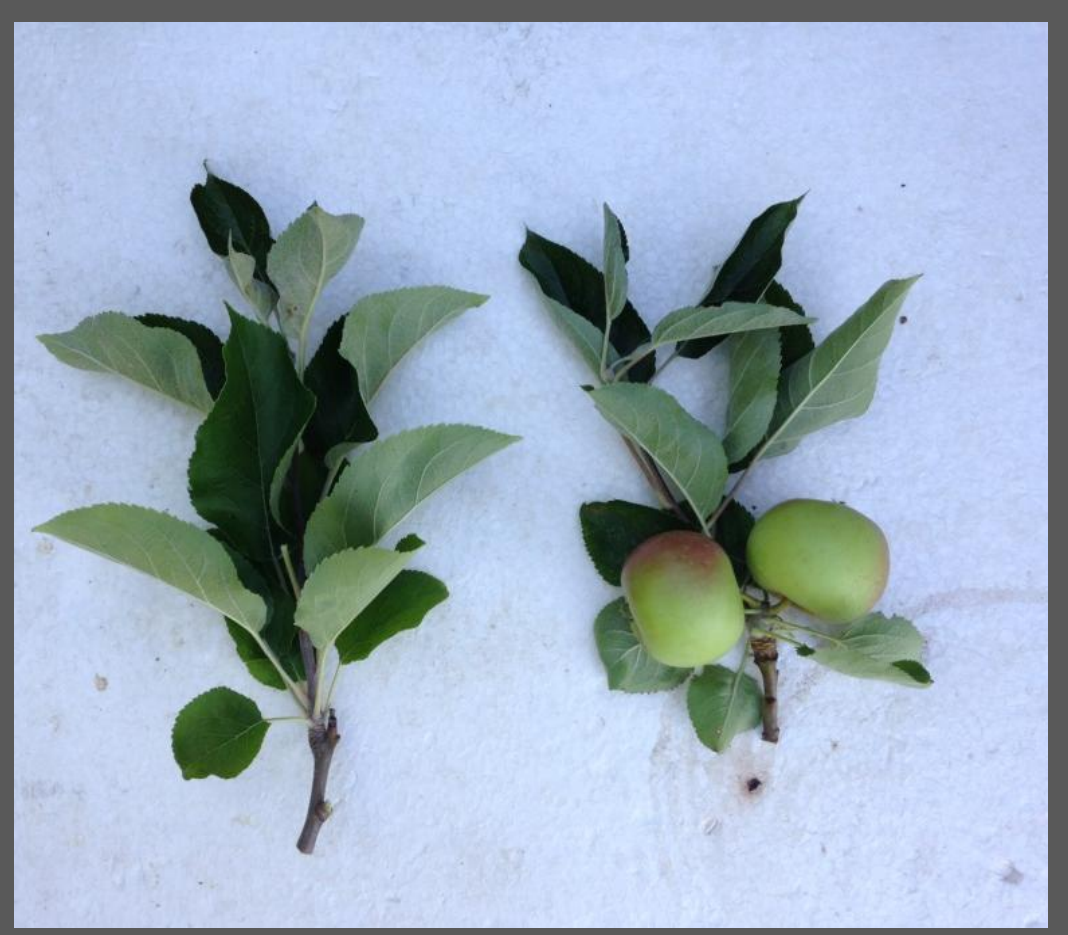




\section{Physiological measurements}

- Estimation of source activity (photosynthesis measurements under non limiting environmental conditions. (3-6 reps per tree and harvest dates)

- NSC analysis on 1 year-old shoots, internodes of annual shoots and leaves.

- Morphological measurements (leaf number, shoot length, SLA ... )

Harvest dates:

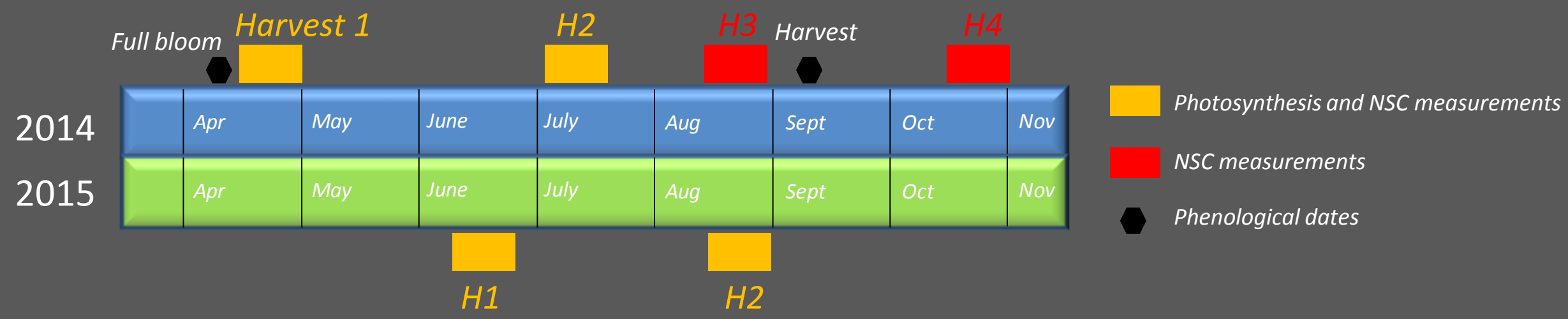

Very large dataset $(\approx 250$ Pn measurements, 450 shoots, 1600 NSC samples) 


\section{Results - Shoot morphology}

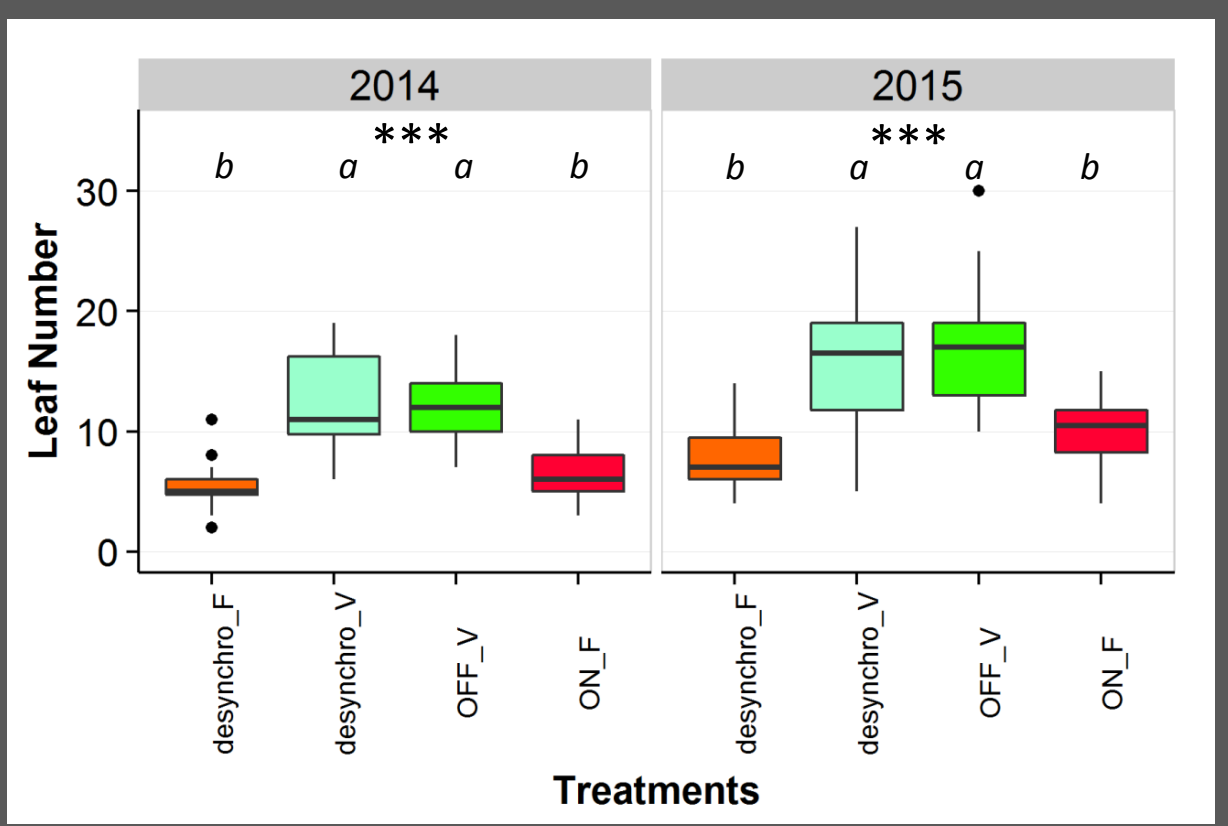

- Shoot growth is mainly determined by the types of shoot itself. (Vegetative > bourse shoots)

- Whatever the global context in which bourse or vegetative shoots grew they reached almost the same size. 


\section{Results - Source activity}

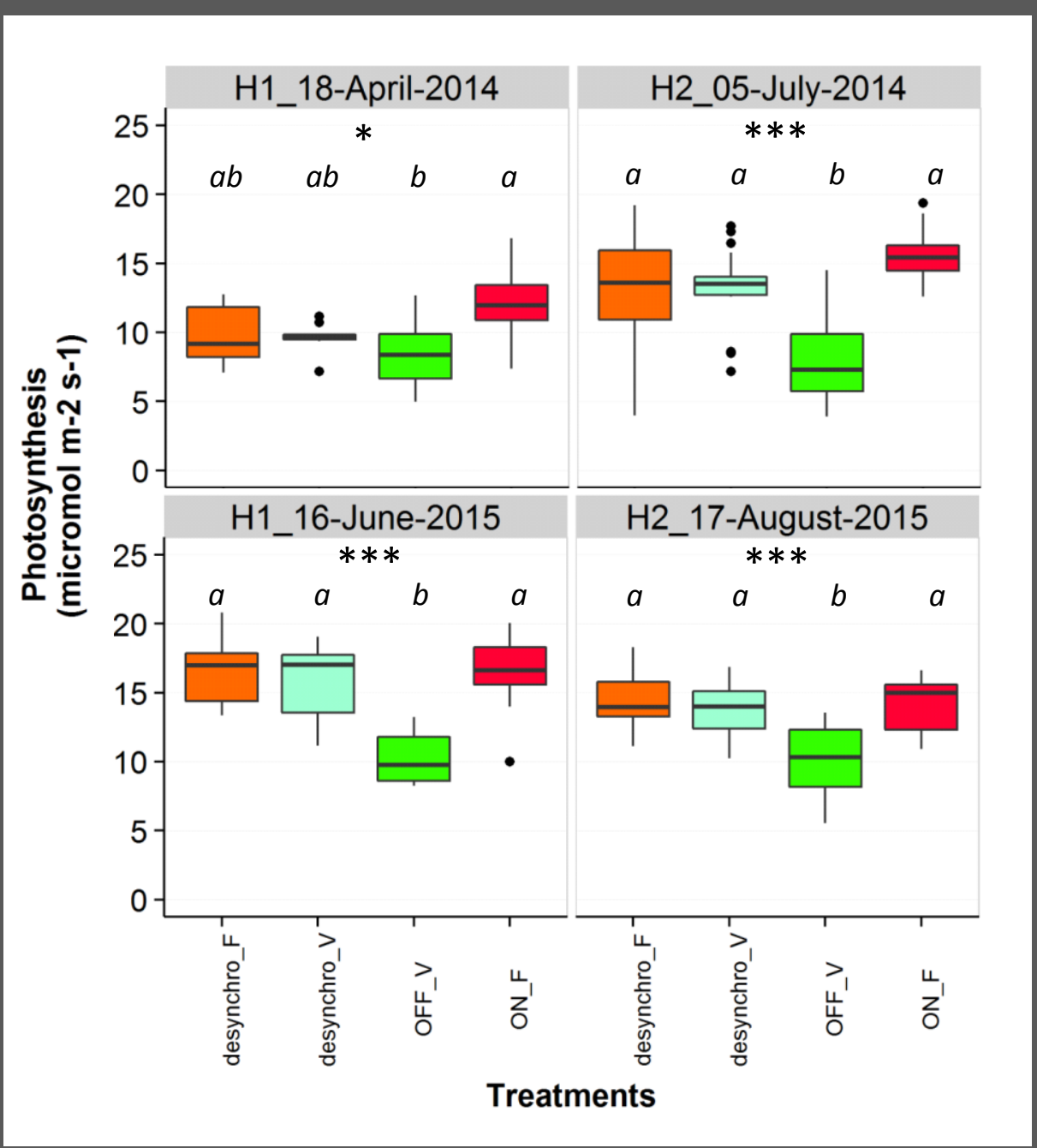

- Vegetative shoots under low crop load condition (OFF_V) display a lower photosynthesis rate. 


\section{Results - Source activity}

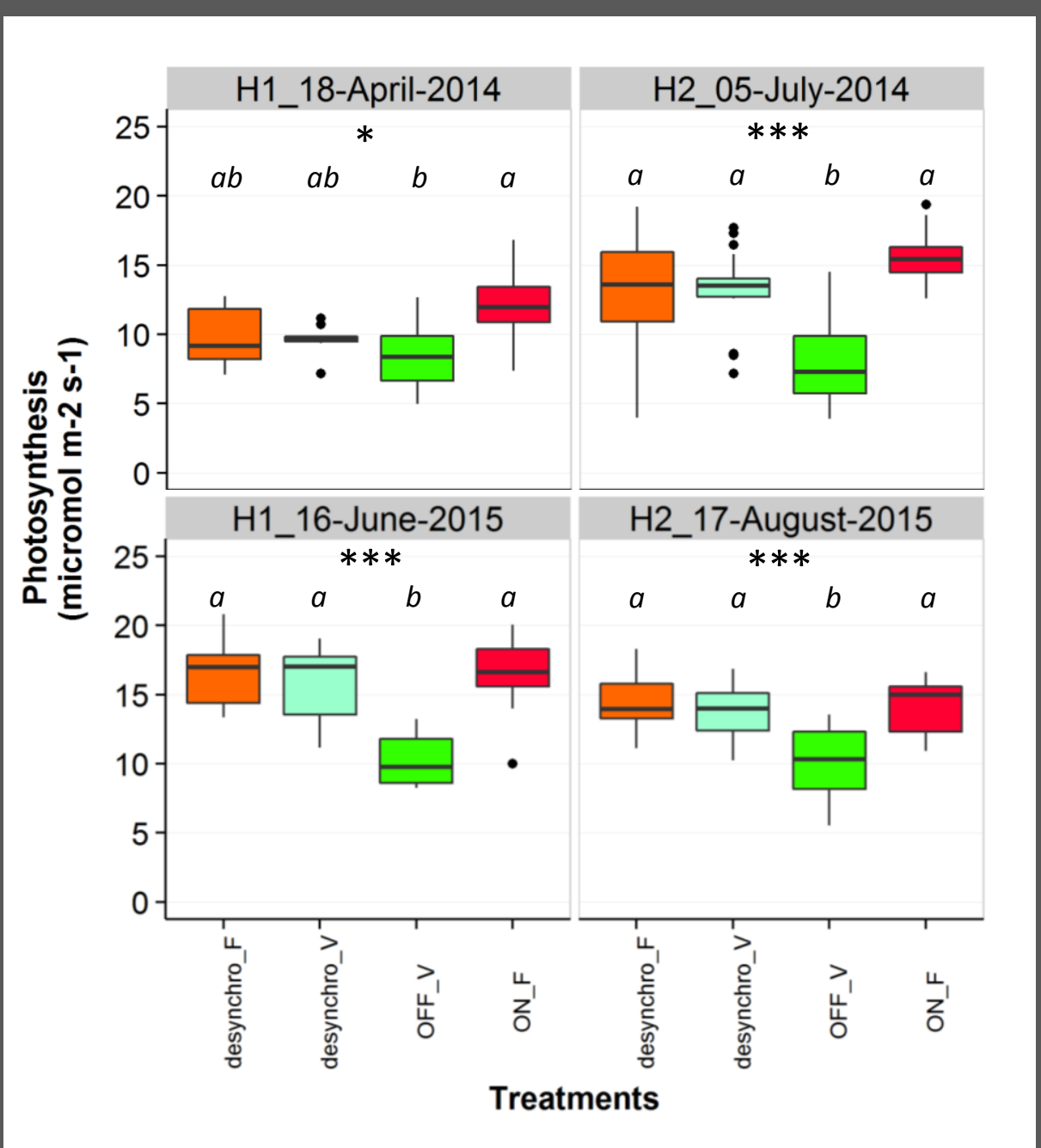

- Vegetative shoots under low crop load condition (OFF_V) display a lower photosynthesis rate. 


\section{Results - Source activity}

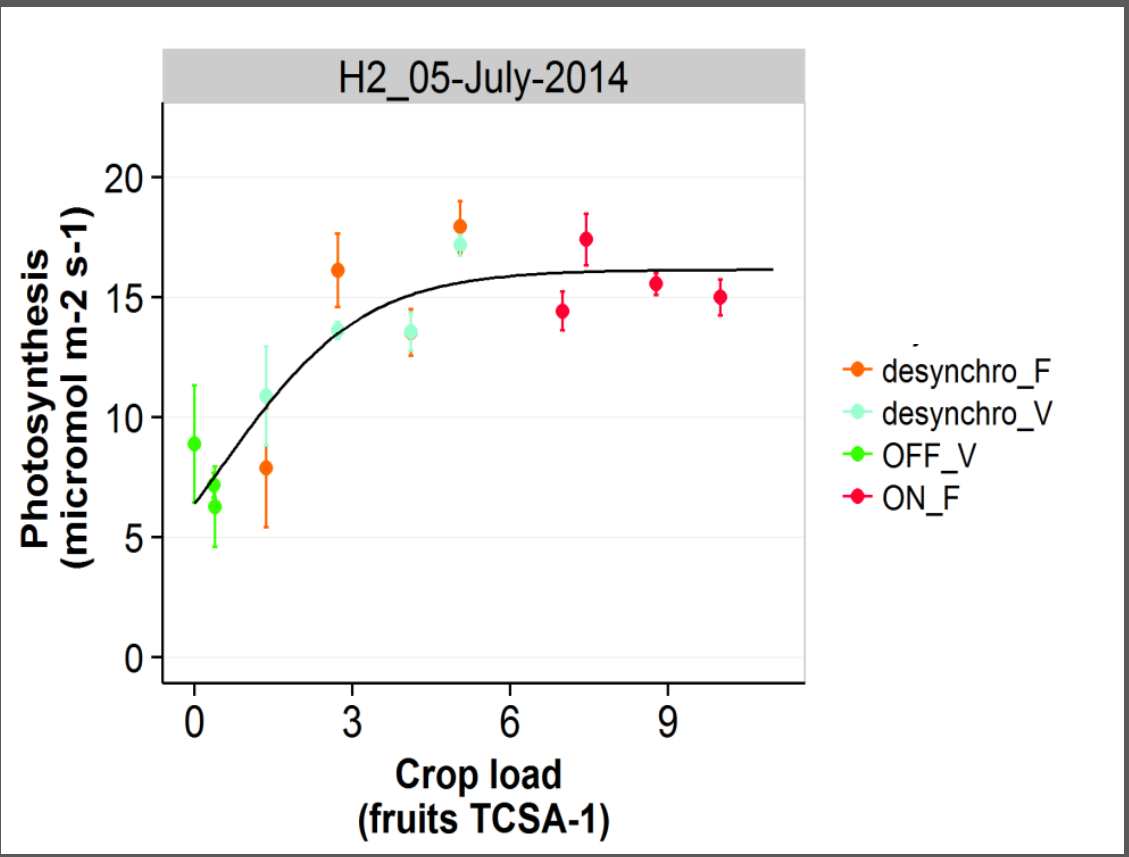

- Vegetative shoots under low crop load condition (OFF_V) display a lower photosynthesis rate.

- A non linear relationship between Pn and crop load is observed and Pn of vegetative and bourse shoots are identical in desynchronized trees (global regulation...). 


\section{Results - Soluble sugars}

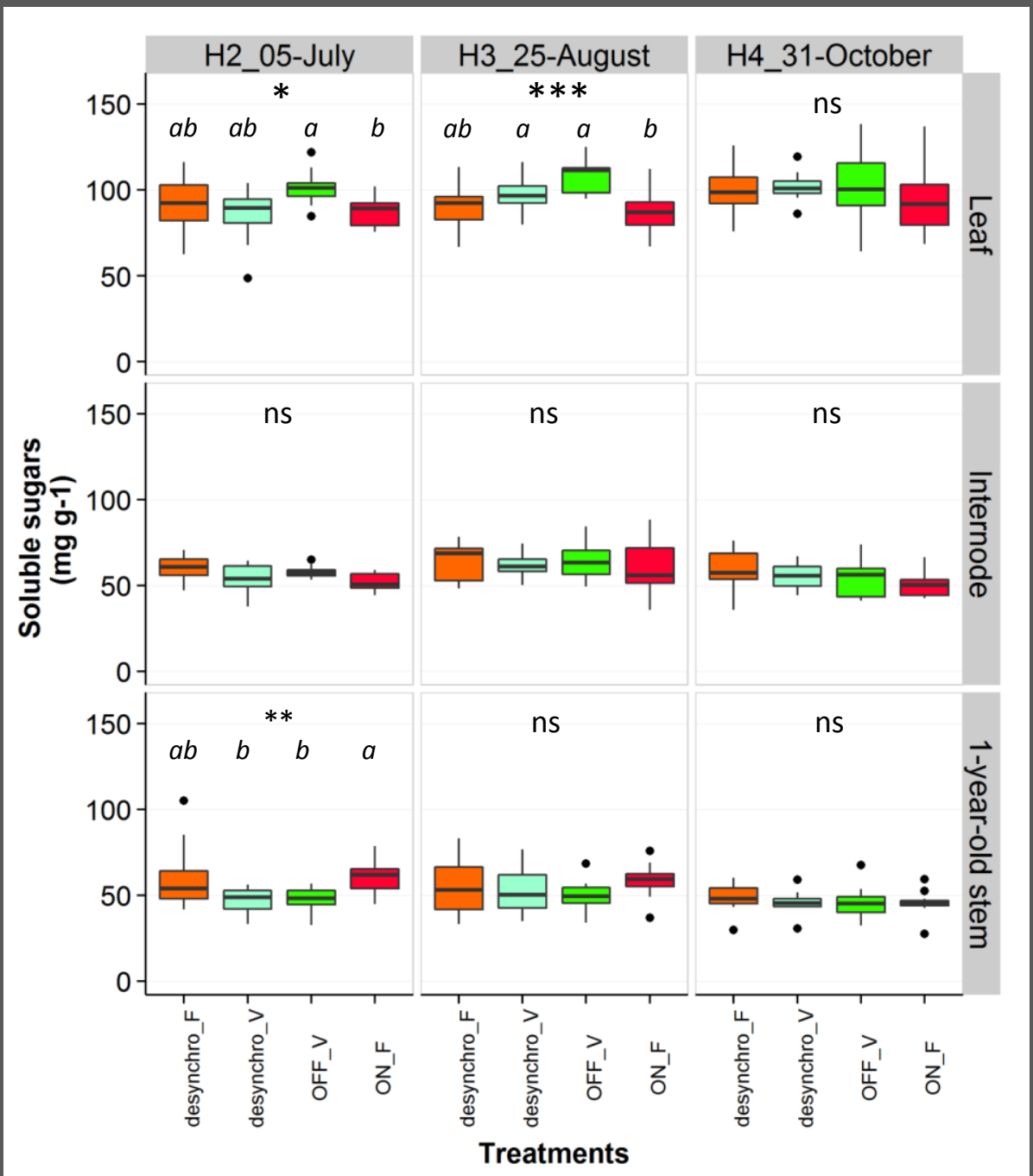

- Differences between treatments for soluble sugars are low.

- A lower soluble sugar concentration for ON trees can be observed in leaf but these differences dissappear in other organs (higher export rate of sugars under high crop load conditions ?). 


\section{Results - Soluble sugars}

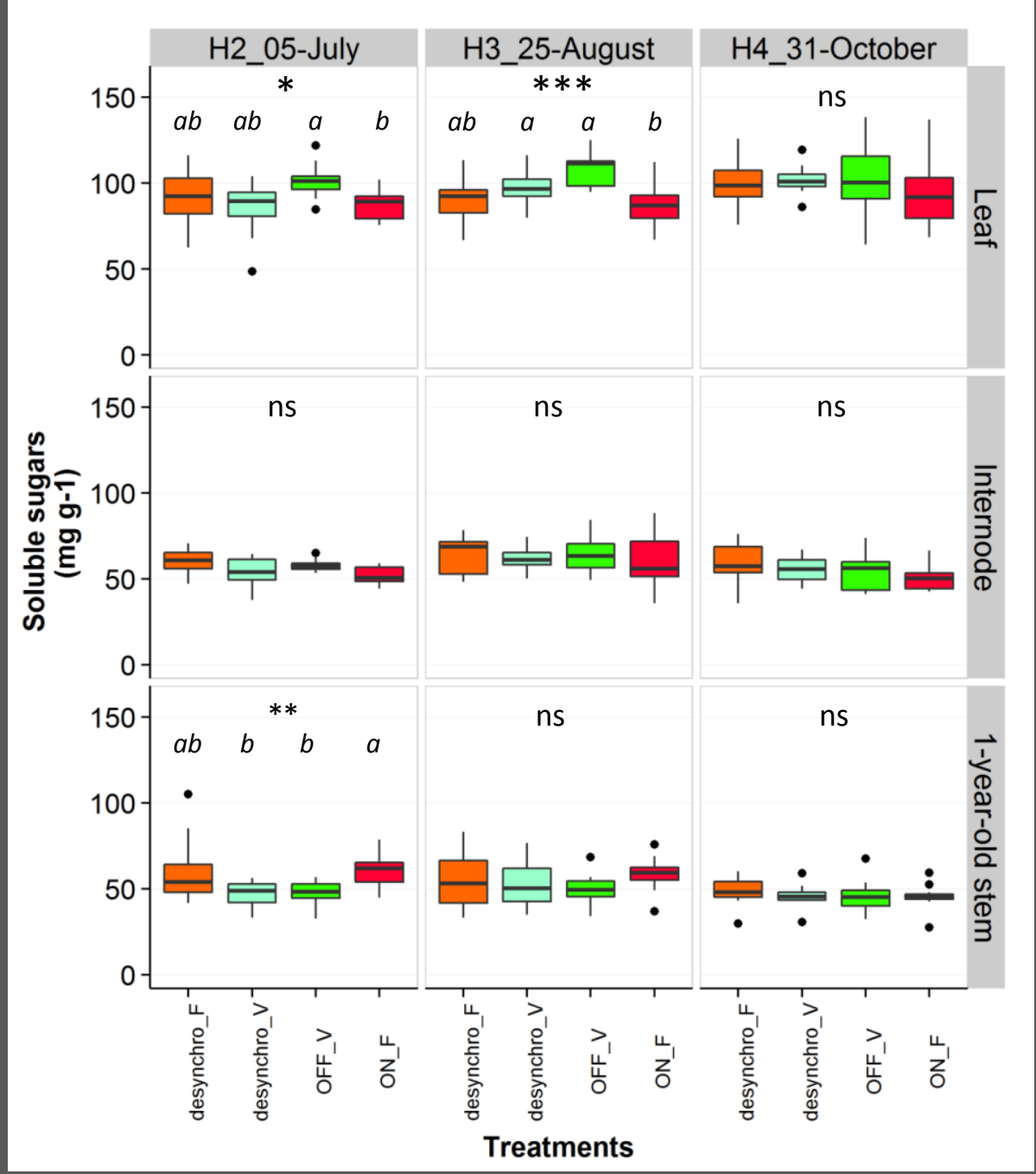

- Differences between treatments for soluble sugars are low.

- A lower soluble sugar concentration for ON trees can be observed in leaf but these differences dissappear in other organs (higher export rate of sugars under high crop load conditions ?).

- Treatments also involved changes in soluble sugar proportions. (less sorbitol compared to other soluble sugars for ON trees).

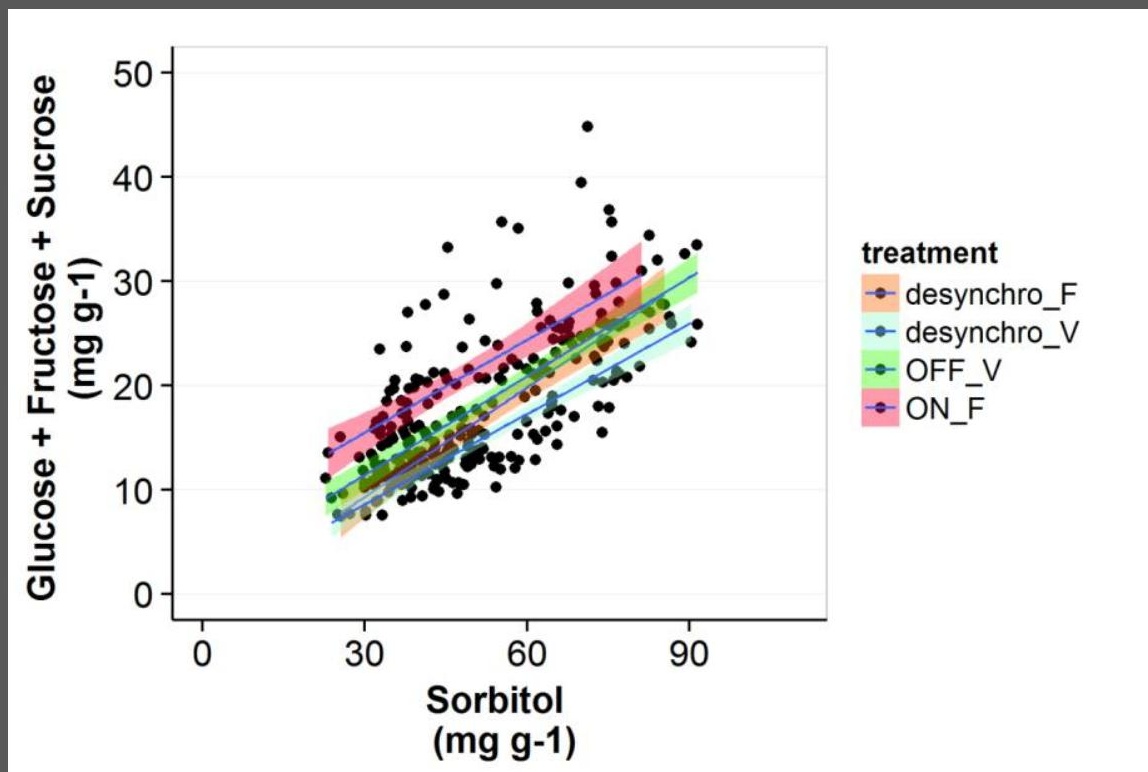




\section{Results - Carbohydrate storage}

- Starch is accumulated in leaves under low crop load conditions, only.

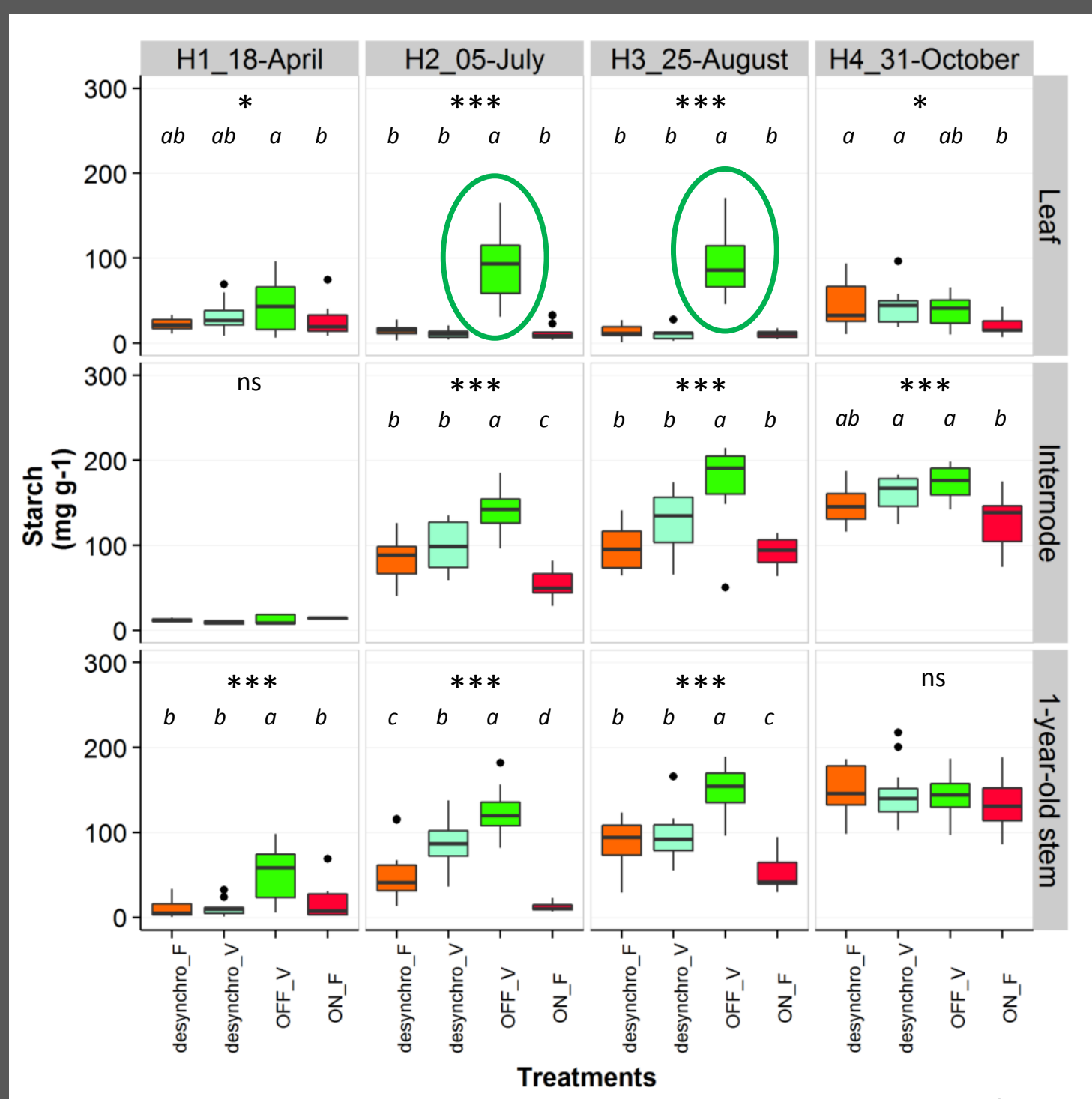




\section{Results - Carbohydrate storage}

- Starch is accumulated in leaves under low crop load conditions, only.

- Starch concentration increases with time in internodes and 1-y-old stems but more slowly under high crop load conditions

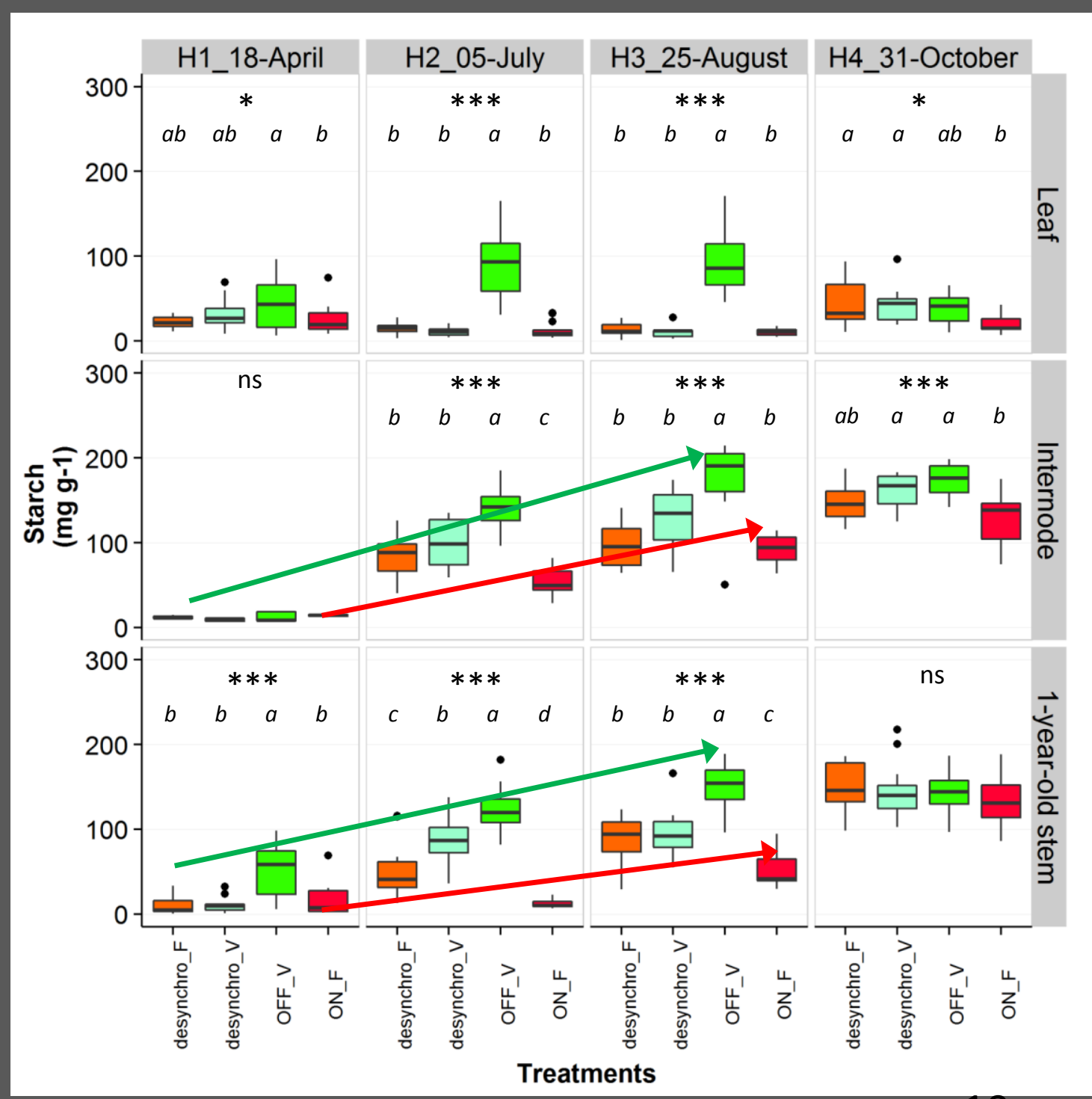




\section{Results - Carbohydrate storage}

- Starch is accumulated in leaves under low crop load conditions, only.

- Starch concentration increases with time in internodes and 1-y-old stems but more slowly under high crop load conditions

- Starch accumulation in vegetative and bourse shoots seems determined at a global level by the tree crop load ...

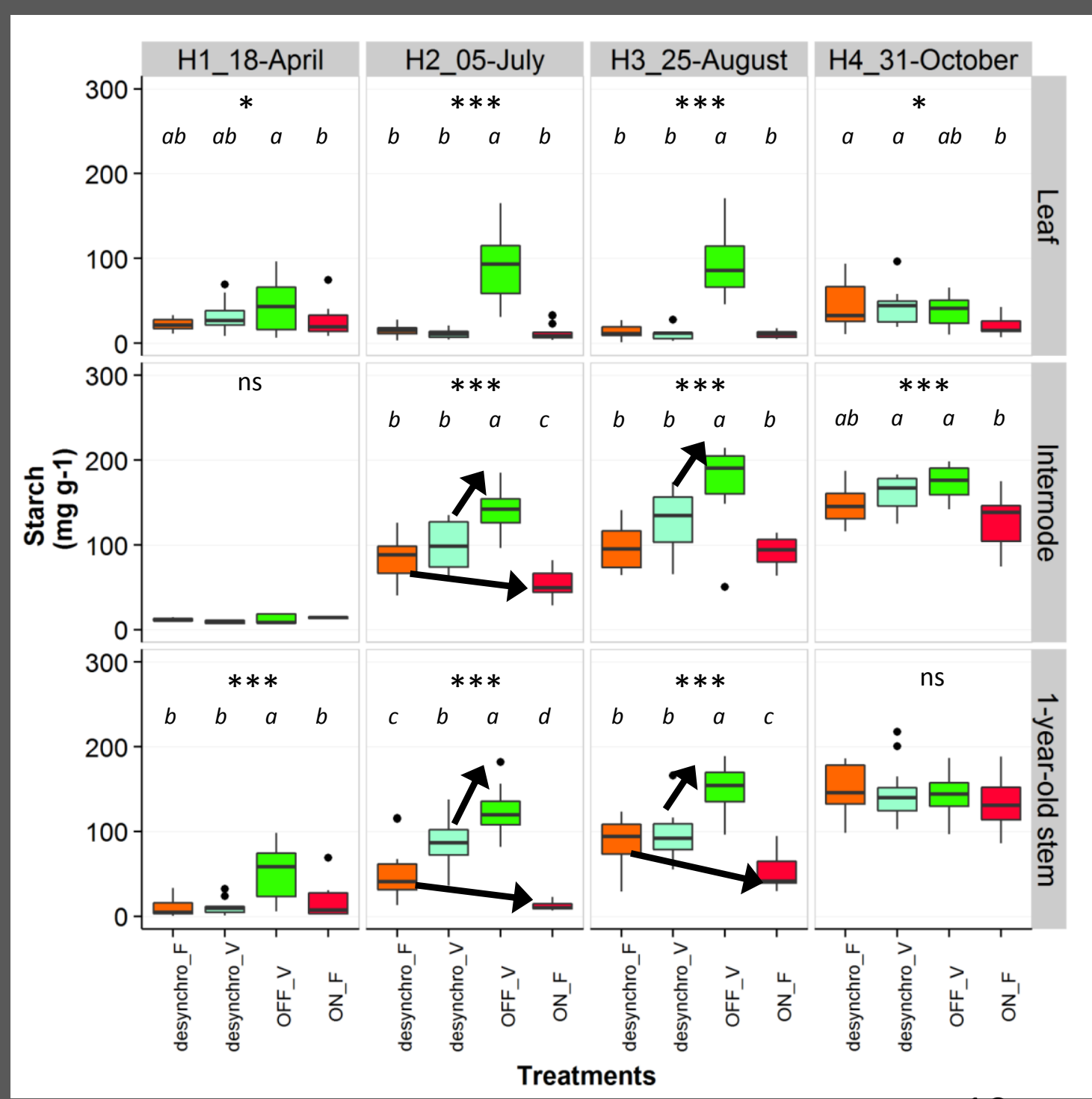




\section{Results - Carbohydrate storage}

- Starch is accumulated in leaves under low crop load conditions, only.

- Starch concentration increases with time in internodes and 1-y-old stems but more slowly under high crop load conditions

- Starch accumulation in vegetative and bourse shoots seems determined at a global level by the tree crop load ...

... but also appears to be slightly associated with the type of shoot for desynchronized trees.

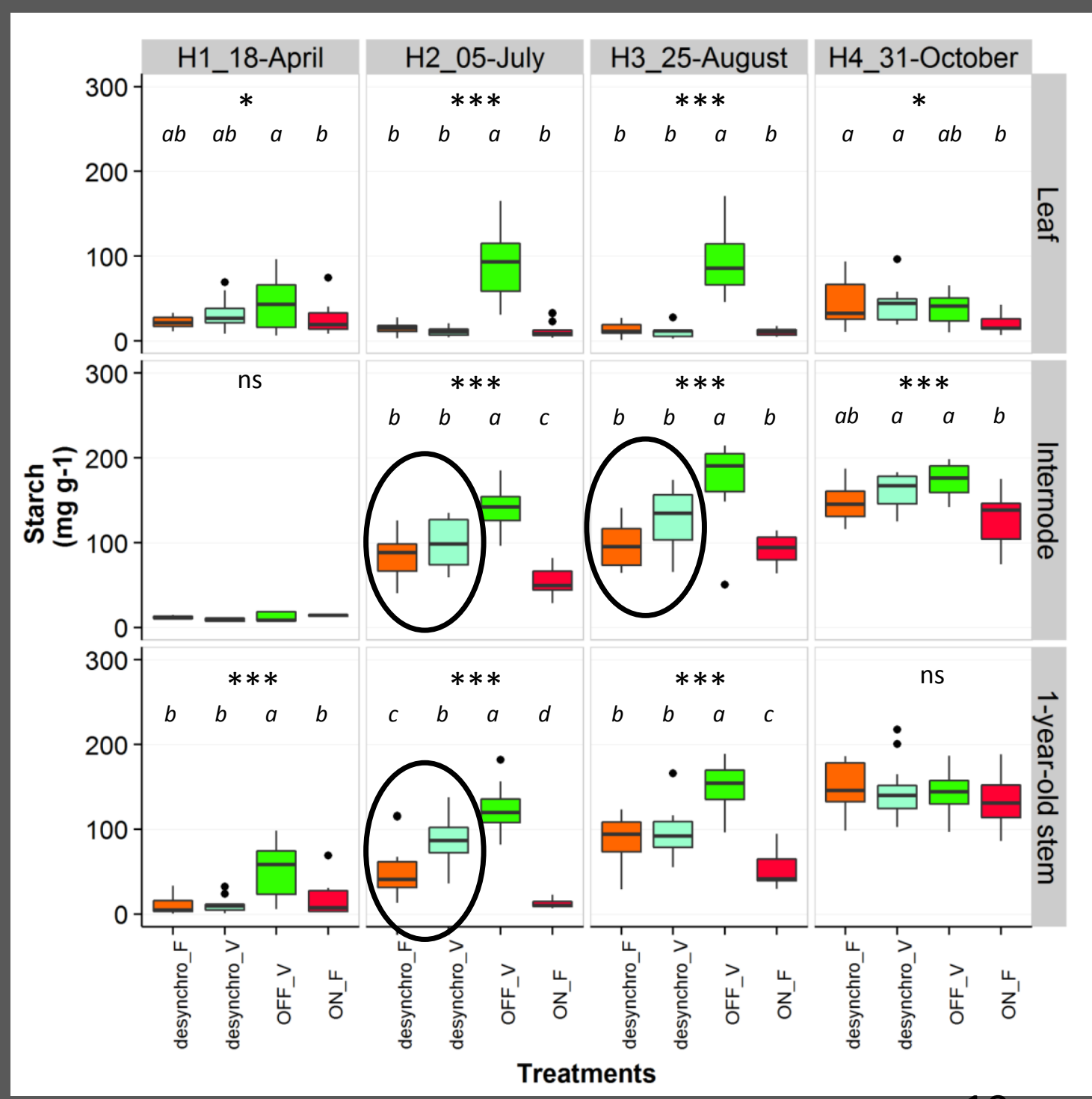




\section{Results - Carbohydrate storage}

- Starch is accumulated in leaves under low crop load conditions, only.

- Starch concentration increases with time in internodes and 1-y-old stems but more slowly under high crop load conditions

- Starch accumulation in vegetative and bourse shoots seems determined at a global level by the tree crop load ...

... but also appears to be slightly associated with the type of shoot for desynchronized trees.

- Differences between treatments tend to disappear after harvest

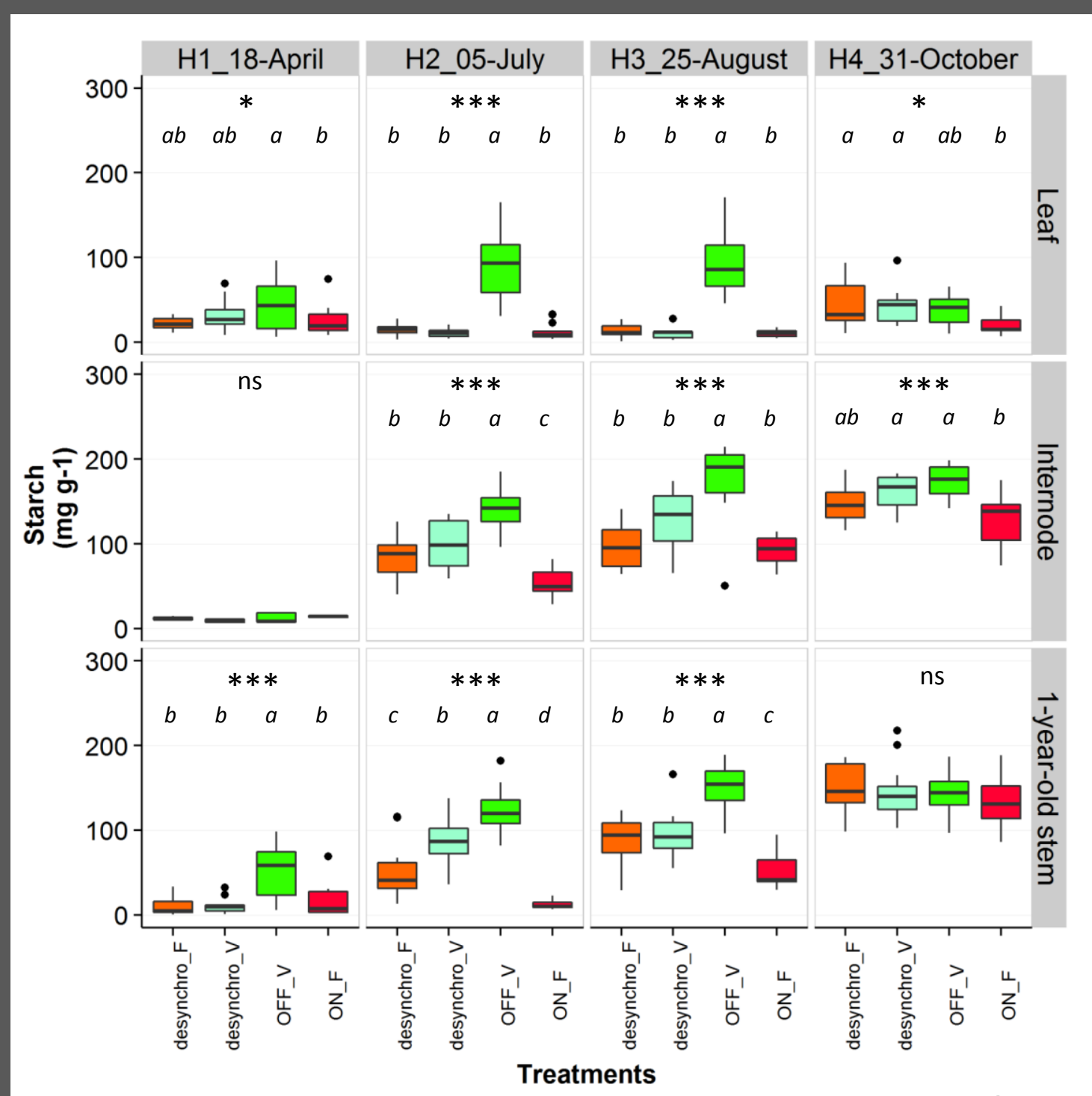




\section{Conclusions}

- This study confirms some already known results (higher rates of photosynthesis under high crop load conditions, higher carbohydrate storage under low crop conditions, e.g Wunche et al., 2000; 2005; Palmer et al., 1997).

- But it also revealed that source sink relations can be determined at different scales of plant organization :

- Pn is mainly determined by the tree crop load.

- Shoot growth is determined by the type of shoot (local scale). 


\section{Conclusions}

- This study reveals that carbon availability in ON trees is lower than in OFF trees with possible impacts on floral induction in meristem (consistent with other molecular studies, Guitton et al., 2016; Haberman et al., 2016)

- But no clear difference was observed between bourse and vegetative shoots of desynchro trees whereas meristem fate of both shoots was different.
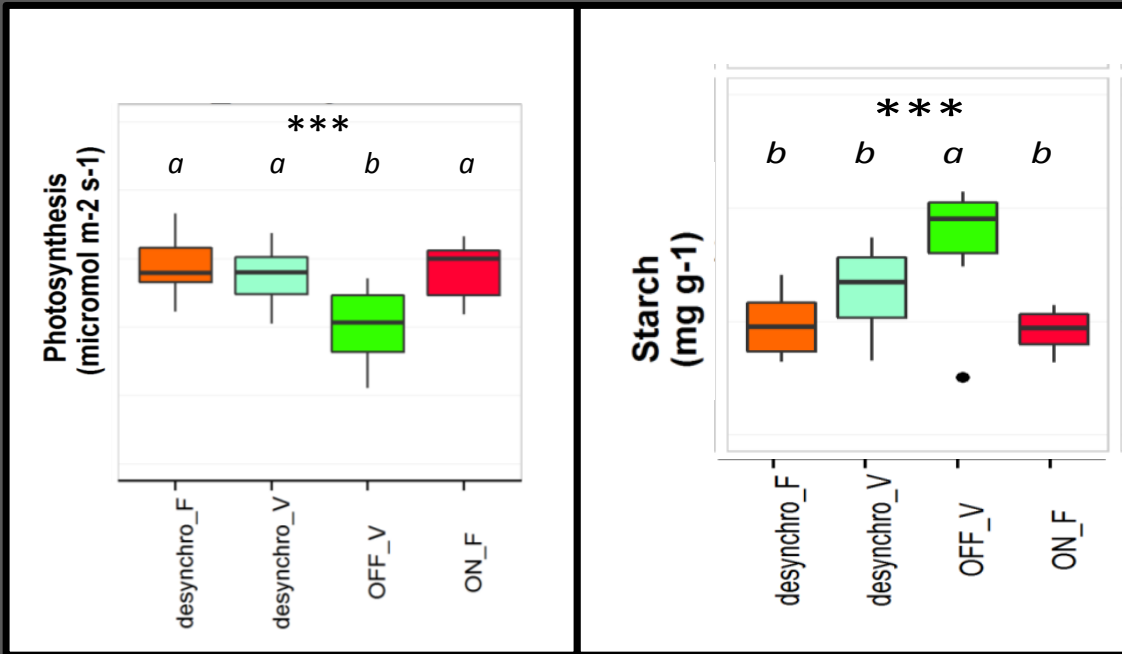


\section{Thank you for your attention}

Acknowledgements:

- AFEF team of UMR AGAP

- A. Clément-Vidal, A. Soutiras (biochemical platform of UMR AGAP)

- Lucie Petit, Loriane Langlade and Benoit Duong (post graduate students of Montpellier and Rennes universities)
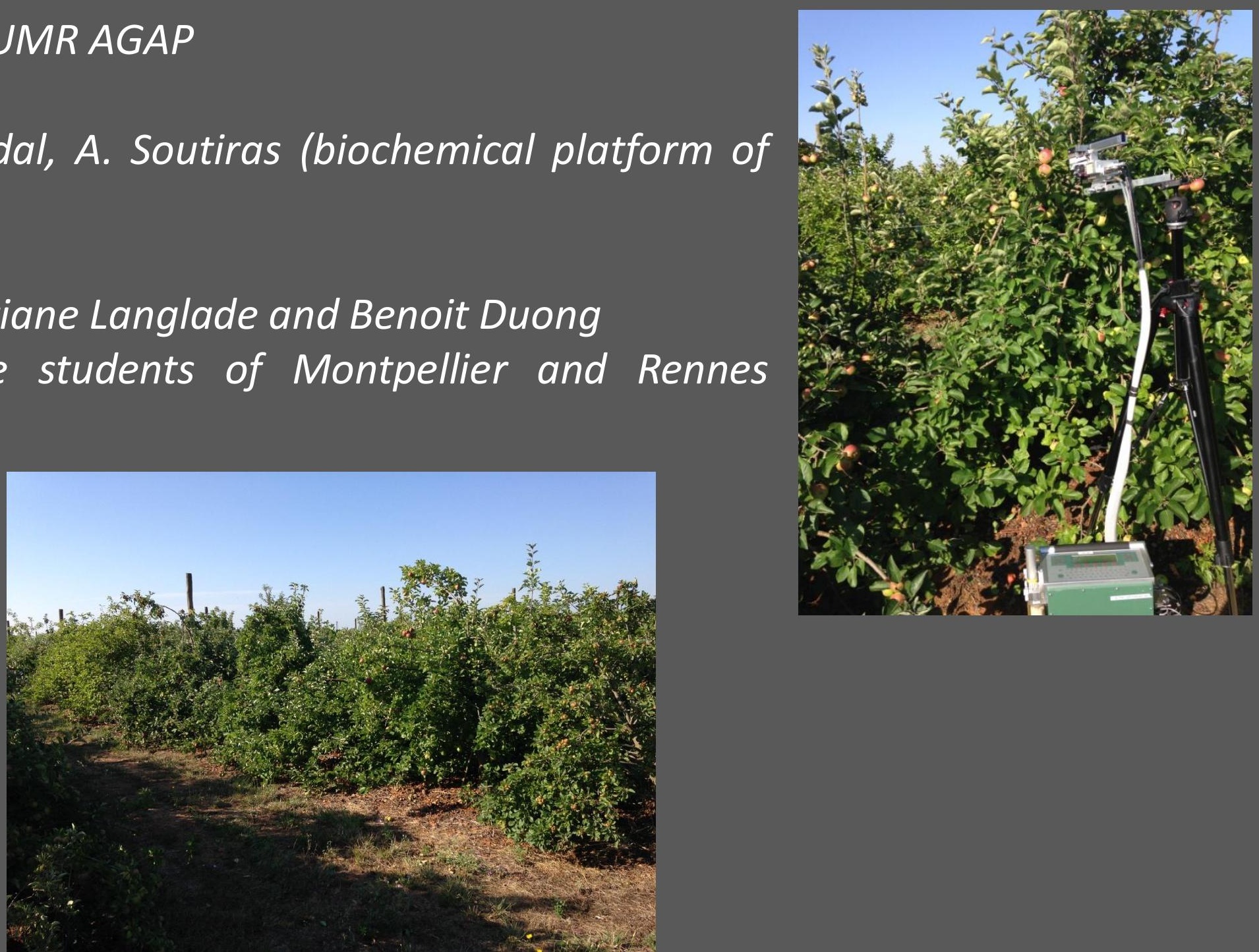


\section{Results - Soluble sugars}

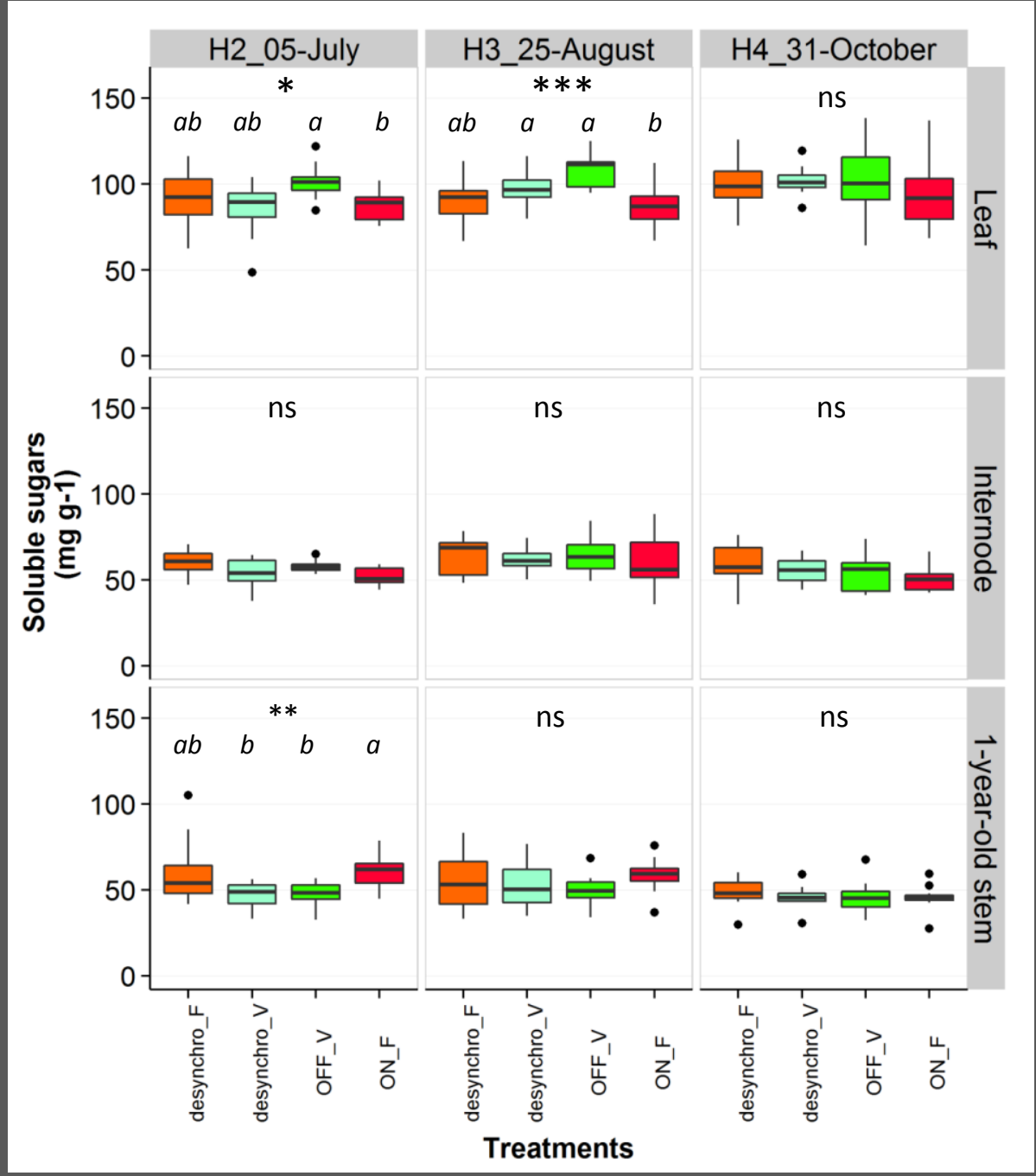

- Differences between treatments for soluble sugars are low.

- A lower soluble concentration for ON trees can be observed in leaf but these differences dissappear in other organs (higher export rate of sugars under high crop load conditions ?).

- Treatments also involved changes in soluble sugar proportions. (less sorbitol compared to other soluble sugars for ON trees).

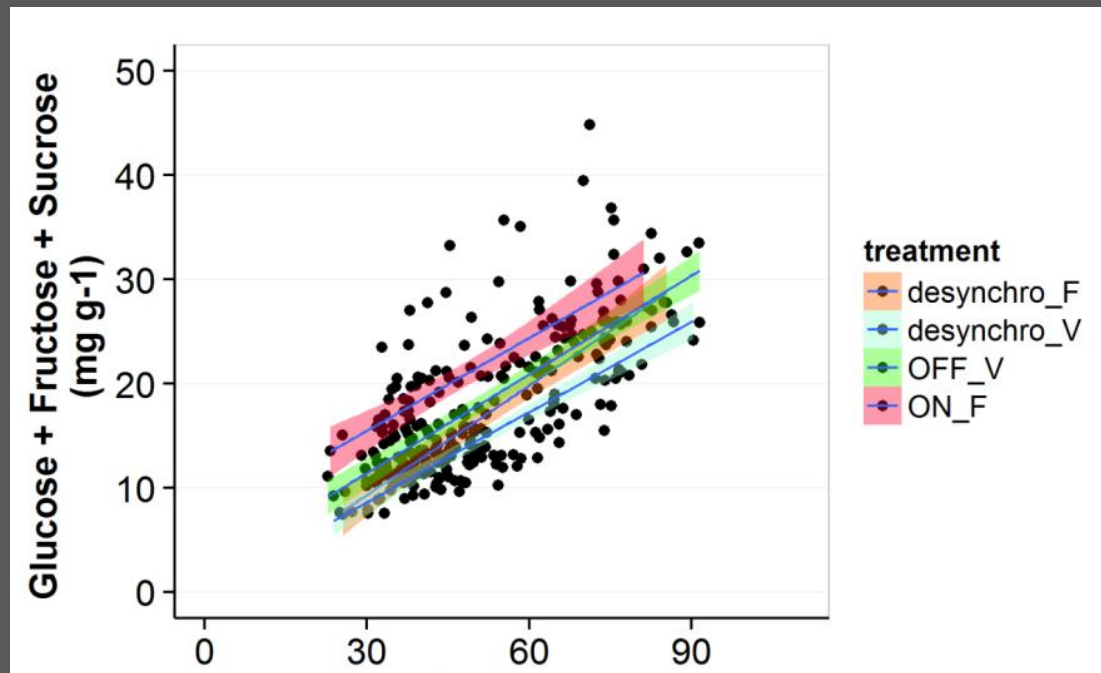

